\title{
STEM STUDENTS' PERCEPTION OF GENDER MAINSTREAMING IN TEACHING: THE DEVELOPMENT OF A MEASURING TOOL
}

\author{
M. Alsina, E. Mas de les Valls, C. Martínez, D. Pino, M. Peña, C. Barahona- \\ Fuentes
}

Universitat Politècnica de Catalunya, BarcelonaTech (SPAIN)

\begin{abstract}
This study assesses the development process of a tool to measure students' perceptions of gender mainstreaming in STEM (Science, Technology, Engineering and Mathematics) studies. Within the framework of a pilot project named Gender Dimension in Teaching implemented at the Universitat Politècnica de Catalunya, UPC-BarcelonaTech, a group of 35 lecturers worked during one semester on how to introduce the gender perspective in their teaching. The project focuses on the four pillars of teaching (i.e. contents, classroom management, methodology and assessment), which were revised from a gender perspective. Within each pillar, gender issues were identified according to the experienced perception of the project participants. However, uncertainty aroused concerning the reliability of such a perception. Indeed, teachers' perception might be influenced by stereotypes and prejudices that could alter the identification of gender issues. Hence, it became obvious that more reliable data concerning students' perceptions was needed. To this end, a first test was cooperatively developed using Google Forms. The survey was tested at the beginning of the semester in 8 different UPC degrees, both at Bachelor and Master level, obtaining more than 500 answers. Despite some interesting preliminary results, a detailed revision of the questionnaire was conducted in order to remove some acquiescence bias and formal errors, thus improving the quality of the survey for a more global study. The improvement process included discussions among the members of the Gender Dimension in Teaching project, discussions with some UPC students' associations and suggestions form experts in survey definition. The revised questionnaire was tested and discussed with a small sample of students. As a result, an improved questionnaire to assess student's perceptions of gender mainstreaming in STEM studies has been cooperatively obtained, which may become an essential tool for further studies extended to all the university community.
\end{abstract}

Keywords: Gender mainstreaming, higher education, STEM, students' perceptions.

\section{INTRODUCTION AND CONTEXT}

The need to incorporate the gender perspective in university teaching is a central issue in gender equality policies within the European Union (EU). Gender equality affects the performance of teaching and research and should help students understand the underlying gender norms in society, as well as their intersection with other axes of inequality (ethnicity, social class, sexual orientation or functional diversity). In addition, the incorporation of the gender perspective in teaching should provide an equitable look to understand inequalities due to sex-gender and sexuality and to bear in mind their implications throughout the learning process [1]. From the EU, Spain has been called upon to fulfil its international commitments on education and gender equality with recommendations such as ensuring the elimination of gender stereotypes from textbooks, the inclusion of women's rights in curricula, the promotion of gender equality in teacher professional training and the demand that gender training be not relegated to the background.

The interest in the introduction of the gender perspective into regulated studies at the Universitat Politècnica de Catalunya, UPC-BarcelonaTech (UPC, www.upc.edu) is not surprising, as this university has been involved in gender projects since many years ago (for example, the project TECNOIA at the end of the 90s, or the Dona Program in 1997). Currently, through the implementation of the III Gender Equality Plan 2016-2020, this university promotes actions aimed at ensuring nondiscrimination, as well as fostering gender policies such as T'steam [2], + GirlsTIC, M2m, Time Reform and Glass Roof, among others [3]. In addition, the UPC is a member of a European project $\mathrm{H} 2020$ (GEECCO, 2017-2021), which encourages the development of equality plans in research institutions (such as universities) and the incorporation of the gender perspective in teaching as its main axes.

The Gender Dimension in Teaching project [4] constitutes part of these actions and includes a pilot experience that was developed at the UPC during the academic year 2018-19. Its main objective was 
to initiate the training of academic staff, giving them the appropriate tools, so that they could redefine their courses incorporating the gender perspective in teaching. The final aim would be to integrate this much needed perspective in all the curricula of the UPC, in the medium-long term in order to comply with the requirements of the Catalan university system quality assurance agency (AQU), which enforces the incorporation of the gender perspective in the all the bachelor's and master's degrees in tertiary education in Catalonia by 2021. According the AQU framework document [5] four fundamental pillars were considered: course contents, teaching methodology, classroom management and assessment processes. Each pillar was reviewed from a gender perspective and gender issues were identified according to the experienced perception of the project participants. The project engaged 35 voluntary lecturers, who cover a wide range of STEM studies, including Architecture, Civil Engineering, ICT Systems Engineering, Naval Systems and Technology Engineering, Aerospace Systems Engineering, Applied Telecommunications and Engineering Management, Industrial Engineering and Environmental Pathways for Sustainable Energy Systems. In addition, this project was also intended to develop a guide of recommendations to be used by all the teaching staff at the UPC. Finally, special attention was paid to the development of indicators that would allow the evaluation of the project after its completion.

Within the frame of the project, the participants designed and implemented gender perspectives activities in their subjects. To be able to assess the effect of these activities on students' awareness, the necessary tools had to be developed. To this end, a pre-test and a post-test were created [6], [7]. The pre-test consisted of a series of subject-specific questions to learn about students' knowledge, reasoning and prejudices before implementing the activities. In the post-test, the same questions were repeated to quantify changes and so analyse the possible improvement with respect to students' gender bias and awareness. However, at the stage of definition of the pre-test questions, uncertainty aroused concerning the reliability of project participants' perception of students' gender bias and awareness. Indeed, teachers' perception might be influenced by stereotypes and prejudices that could alter the identification of gender issues. Hence, it became obvious that more reliable data concerning students' perceptions was needed. A dedicated test was built as a response to this need. The initial development of the test was cooperatively done among all the participants in the Gender Dimension in Teaching project. After gathering all the replies, the test was revised. This more detailed analysis has been carried out by the authors of the present research.

Actually, as for the fundamental aspects of the Gender Dimension in Teaching project, it made sense to study the student's perception of gender mainstreaming in teaching throughout a bachelor's or master's degree. This way, a first questionnaire would be carried out at the beginning of the studies (during the first year's second semester) and it would be repeated again at the end of the degree, coinciding with the elaboration of the Bachelor's or Master's degree final thesis. The collaborative work done in this direction has started with the test mentioned before and has resulted in a contrasted questionnaire, applicable to the study of the gender perspective in university teaching. The questionnaire development process was based on the active participation of teaching staff from different STEM degrees, consisted of different stages, and applied a questionnaire revising methodology to obtain the maximum reliability. Hence, the research sought the implication and guidance of two main agents: professionals in the area of statistics and sociology concerned with opinion polls and studies and students' associations, which are the recipients of the questionnaire, specially groups sensitive to gender issues such as the Feminist student association. Therefore, the present work constitutes a good example of collaborative work and methodology.

The present work intends to summarise the participative process that led to the elaboration of this enhanced questionnaire. An analysis of some sample answers is being conducted at the time this paper is being written. However, the students' perception on the degree of gender perspective in UPC teaching is out of the scope of the present study. The aim of this paper is to describe the process leading to the definition of this new improved survey. The description of the resulting questionnaire and students' perceptions are included in section 3.4.

\section{METHODOLOGY}

The development of a questionnaire to detect students' perceptions of gender mainstreaming in teaching at the UPC was a paramount challenge for the teaching staff of scientific-technological areas. The starting point was the participation in the Gender Dimension in Teaching project [4] implemented at the UPC and as a reference similar experiences and projects carried out at other universities were considered [6]-[8]. However, most of them were not directly related to STEM. Therefore, this study is 
mainly based on the experience and implication of teaching staff from different degrees taught in a university renowned in the area of technology and engineering.

The development of the questionnaire consisted of different stages and followed an analytical methodology, from constructing a hypothesis to obtaining a final result, going through the design, implementation, analysis, comparison and assessment stages. This section includes a general description of the methodology applied in the different stages. The details concerning the contents and the results of each stage will be described in the following section.

\subsection{Stage 1: Design of survey content}

The first stage consisted in the analysis of the context presented in the previous section with the aim of determining the study working hypotheses. The task was carried out by multidisciplinary work groups, which identified common aspects in different disciplines to address gender issues. Thus, the first step was to find gender issues related to each fundamental pillar [5], namely: (a) course contents, (b) teaching methodology, (c) classroom management and (d) assessment process. The result was the formulation of several hypotheses.

\subsection{Stage 2: Questionnaire design}

Once hypotheses were defined, the second stage was aimed at the development of the questionnaire. The methodology consisted in an online cooperative work (via UPC ATENEA platform) to formulate questions divided into different sections. The authors of the present study took an active role working on gender issues and questionnaire defining aspects. The result was a questionnaire developed with Google forms [4].

\subsection{Stage 3: Sample students test}

In the third stage students played an important role. It is crucial to consider the actual respondents of the questionnaire and not simply those the questionnaire is meant for, namely, students sensitive to gender issues. Thus, a good way to do this was to check the survey with a good sample of respondents (with a representative participation of both boys and girls). The questionnaire was tested at the beginning of the second semester of the academic year 2018-19 in eight different UPC degrees, both at Bachelor and Master level, by members of the Gender Dimension in Teaching Project. A link to the electronic version of questionnaire was presented at the beginning of the lecture, in the classroom, to facilitate the participation of students and to measure the time students spent responding it. In addition, students' reactions, questions, etc. were also observed.

\subsection{Stage 4: Review sample answers}

The fourth stage included the revision of the responses obtained to determine weaknesses, their origin and typology and ways to improve them. The exchange and sharing of experiences revealed different interpretations and the need to perform a quality review.

\subsection{Stage 5: Focus groups}

The fifth stage would encompass the interviews carried out with different groups of students: (1) the Feminist Assembly from Barcelona School of Industrial Engineering (ETSEIB) and (2) Students' Delegation of Castelldefels School of Telecommunications and Aerospace Engineering (EETAC). It is important to point out the interest of both groups in the revision of the questionnaire and the question format. Their comments have been included in section 3.3.

\subsection{Stage 6: Learning from experts}

After this exchange of experiences, a space for reflection was opened for all project members and the sixth stage was initiated. This stage was devoted to offer specific training to project members concerning the definition of questionnaires. To this end, the UPC Science Education Institute (ICE) organized a training course taught by Beatriz Galindo, from the Opinion Studies Centre of the Government of Catalonia. 


\subsection{Stage 7: Reviewing and improving}

The seventh stage, the natural consequence of the other six stages, consisted in an iterative process among the authors of the present study and experts in the field of opinion studies. First with Beatriz Galindo, the teacher trainer, and then with Mireia Ventura, a professional statistician. At the end of this stage, a questionnaire was developed incorporating improvements to correct previous weaknesses.

\subsection{Stage 8: Sample group test}

The questionnaire developed in the previous stage required a new validation. Therefore, during this phase a pilot study was carried out with a reduced number of students to detect further errors. For this pilot study, a new group of students from the student association of Manresa School of Engineering (EPSEM) representing six different degrees was selected. The Feminist Assembly of the School of Industrial Engineering of Barcelona (ETSEIB) and the Students' Delegation of Castelldefels School of Telecommunications and Aerospace Engineering (EETAC) also collaborated again. From their comments, new improvements were incorporated in the questionnaire.

The process was completed with the development of a new questionnaire, that follows the pre-test and post-test methodology, with the aim of identifying students' perceptions of gender mainstreaming in teaching. Moreover, the gathered information could be useful for the design of the gender perspective activities at subject level.

\section{RESULTS}

\subsection{Design of content and questionnaire}

To define the survey content, the first step was to set hypotheses based on the identification of gender issues considering the fundamental pillars (a)-(d) quoted in previous sections from [5]. Hypotheses were formulated as questions so that they could be validated with the questionnaire's results.

The analysis of (a) the contents taught in each course could not be carried out in a global and uniform way. There are generic contents, common to the different engineering fields, such as for example, Mathematics, Statistics or Physics. However, there are some which are much more specific, such as those proper of disciplines like Nautical studies, Architecture, Automotive Engineering, Aerospace Systems Engineering, Applied Telecommunications and Management Engineering. In order not to get into content course specificities and peculiarities, the discussion was centred around an issue common to all of them: the existence of female references in the degree field known by students. This led to the formulation of Hypothesis $\mathrm{H} 1$ :

$\mathrm{H} 1$ : There is a lack of female references in the fields of engineering and architecture.

Actually, there was a general hypothesis motivating the investigation, namely:

H2: Possibly there are students suffering some sort of discrimination on the part of teaching staff or classmates.

For sure $\mathrm{H} 2$ needs to be included in the questionnaire, but the analysis of (b) the teaching methodology used and (c) the classroom management helped us to be more focused. The teaching methodology and the classroom management are interrelated, so the analysis was carried out for both simultaneously, which gave rise to hypothesis $\mathrm{H} 3-\mathrm{H} 6$. On the one hand, some were related to interaction between the teacher and the students (hypothesis $\mathrm{H} 3-\mathrm{H} 4$ ); on the other hand, there are some activities where students work in group autonomously, without direct interaction with the teacher, so then we developed hypothesis $\mathrm{H} 5$.

H3: Girls are more reluctant than boys to ask or participate in front of the class group.

H4: Girls may feel uncomfortable when solving doubts during teachers' office hours (the percentage of male teachers is higher than $75 \%$ ).

H5: In mixed groups roles are distributed following traditional gender stereotypes.

The assessment processes (d) need a more detailed study, so they are not included in this paper. However, perceptions or prejudices could have a lot of influence, so the following hypothesis $\mathrm{H} 6$ was also considered. 
H6: There exist a lot of gender stereotypes, including those stating that girls are not equally as capable as boys to study and work in the field of STEM.

In addition, students' opinions concerning the need of the existence of projects such as the Gender Dimension in Teaching project described in the present study was also observed and monitored.

To collect information related to the hypotheses above, a first attempt of survey was designed with Google Forms comprising three main sections: (1) Personal Information, (2) Professional references and (3) Perceptions as a UPC student. Within the personal Information section, the student is asked to provide some data relevant for our study as sex (three options: male, female, others) and age (within a range). To identify students and so be able to relate pre-test and post-test answers, but keeping them anonymous, an anonymous identifier (by subtracting the birth date to the ID number) is used, following suggestions by García-Holgado [6]. The other two sections include six multiple choice questions and three open ones. The professional references section was short, but the perceptions of UPC students are a very interesting source of information and an extra effort was needed to keep the survey to a reasonable size. This was achieved by grouping questions in a multiple selection grid, according to a common setting and a common Likert scale. Several scales were tested and two scales were selected to be used, depending on the question: on the one hand never, rarely, sometimes, many times, always, and on the other, strongly agree, agree, indifferent, disagree, strongly disagree.

Regarding the topic of the survey, let us point out the importance of using a popular language without including technical terms as, for instance, many students don't know what "gender-sensitive language" means. Finally, the original survey was in Catalan, and the corresponding English version, can be downloaded from the site [4].

\subsection{Analysis of questionnaire from respondent test and statistics}

A first analysis was conducted considering respondent answers. Apart from considering these collected answers, the interaction and comments from students when answering the survey were also observed. At this stage, the point of view of the project members was key to analyse all these gathered data.

In general, the time students spent to answer the questionnaire was fine. Students' answers and interaction also revealed that most questions didn't pose any problem and were easily understood. That was a good indicator when checking measurement errors. Nevertheless, students were surprised by some questions (for instance those asking for the roles they assume in work groups) and were not so confident or have a clear opinion in others. When asked after completing the survey, some of them mentioned that some questions seemed quite similar and repetitive, which didn't encourage them to reply.

Their main remarks concerning the questionnaire were the following:

a) inclusive language needs to be used in the whole survey, in all details.

b) some questions were too similar leading to confusion.

c) questions were too much oriented to detect discrimination against women, when also some men might be discriminated.

d) some questions allowed a general interpretation, in some cases too general, which led to unclear information in the answers.

e) some questions actually assumed (at least partially) some hypotheses, and hypotheses can be false.

f) frequency is not clear when comparing answer by male and female students, because of the absence of parity in class groups.

g) Regarding the question relative to the difficulties encountered by girls, the interpretation can be two-fold. These difficulties could be due to their own limitations and capacities or for external reasons. Therefore, it needs some clarification.

Among the members of the project, the main points of discussion were the following:

1 Some information about students' parents could be interesting, but it was not added to avoid a too long survey. 
2 People was sensitive to the question about capacities/skills. It was not clear how it could be worded, but it is interesting to study answers to quantify "the problem". A new formulation was suggested including a wider range of skills to highlight diversity and to avoid focusing only on a few ones. A list of possible answers is also very important and the option "indifferent" should also be included.

3 The "role in a working group" question only makes sense if the respondent has been in a mixed group of male/female students, so a control question to filter answers is needed. Also, several other roles could be introduced (formatting the document, gathering data, experimental assembly during laboratory practices, leadership, management, note-taking, software calculations). A high percentage of participation in work groups should be required $(>75 \%)$ to collect more significant information.

Despite some interesting preliminary results, a more technical revision of the questionnaire was conducted in order to remove some specification errors, acquiescence bias, primacy and recency effects, social desirability and formal errors, etc. See Table 1 for a list of common errors studied at [9], according to [10], [11]. Thus, the quality of the questionnaire was improved to conduct a more global survey.

Table 1. Most common types of measurement errors, cf [10], pag.9.

\begin{tabular}{|ll|}
\hline A & $\begin{array}{l}\text { Definition problems. The definition of the statistical terms are not known } \\
\text { or are not used by the respondent. }\end{array}$ \\
\hline B & $\begin{array}{l}\text { Memory errors. Most common in individual or household surveys but can } \\
\text { also occur in establishment surveys. }\end{array}$ \\
\hline C & $\begin{array}{l}\text { Respondents must make estimates. The exact information is not always } \\
\text { available or not for the right period. }\end{array}$ \\
\hline D & $\begin{array}{l}\text { Time period problems. The information relates to another reference period } \\
\text { or point in time than that requested, e.g. if an enterprise has a different } \\
\text { financial year. }\end{array}$ \\
\hline E & $\begin{array}{l}\text { Need for calculations. Data for the variable does not exist so the answer } \\
\text { must be calculated from other data. }\end{array}$ \\
\hline F & $\begin{array}{l}\text { Correlated variable used, e.g. when production data is requested but not } \\
\text { available, the respondent answers with data on deliveries.. }\end{array}$ \\
\hline G & $\begin{array}{l}\text { Accounting problems. The enterprise does not have the information } \\
\text { distributed by the categories or object types requested for the statistics. }\end{array}$ \\
\hline H & $\begin{array}{l}\text { Classification errors in the background variables, because they are difficult } \\
\text { to measure. }\end{array}$ \\
\hline I & True value is missing. \\
\hline J & $\begin{array}{l}\text { Inclusion of incorrect components in a variable total. Respondent wrongly } \\
\text { adds components that were not requested. }\end{array}$ \\
\hline K & Errors not noticed on registration \\
\hline L & $\begin{array}{l}\text { Exclusion of components in a total. Respondent neglects to include one or } \\
\text { more components that were requested. }\end{array}$ \\
\hline
\end{tabular}

\subsection{Analysis from some students' associations}

In order to obtain some further opinions from students, several meetings were held with two students' associations: (1) the Feminist Assembly from the Barcelona School of Industrial Engineering (ETSEIB) and (2) the Students' Delegation of Castelldefels School of Telecommunications and Aerospace Engineering (EETAC).

The Feminist Assembly is a group of female students from the ETSEIB born in 2017. They meet weekly to discuss specific topics and organize diverse activities. They offer information, awareness, assessment and support to other female mates. The assembly is defined as a place where all girls can feel comfortable if they need to explain an aggression. They also believe that it is a way of empowering themselves: "we can handle aggressions without the need to ask for help or protection to any man". 
The first meeting that the authors held with this group coincided with the publication of the first survey. Comments on the survey were gathered to improve the writing of various questions, to delete some of them and to add new ones. Specifically, their main proposals were the following:

a) Debate the difference between sex and gender: In order to be respectful with the feelings of the respondents, they argue that people must be asked about gender.

b) Eliminate questions 8.7 and 8.8 . as it is difficult to understand exactly how to measure frequency since the proportion of boys and girls is very unbalanced

c) Eliminate questions 9.4 and 9.5 . If it is assumed at the outset that intellectual capacity depends on sex, then it is offensive.

d) Add a question about respondents' opinion on the impact this topic may have on society.

In parallel, the first survey was shown to the Students' Delegation at EETAC. A dedicated meeting was organized to discuss the survey. The students attending the meeting were particularly fond of the initiative but they had no important remarks to the questionnaire. They were concerned about the fact that the survey would not be answered by all students but only by those of the participating degrees. Obviously, in the frame of the Gender Dimension in Teaching project, just few courses were involved, but the enthusiasm the students showed is a good motivation towards the definition of a global survey for students of all the UPC degrees. Regarding the few courses selected for carrying out the survey, students were also worried about the representativeness of such results.

Once the survey was passed to students and the results were gathered, a second meeting was held with the Feminist Assembly. The aim of this meeting was to present and analyse the results of the first survey and collect new suggestions to continue improving it. The students ratified their opinions and insisted again on the need to eliminate questions about the differences in intellectual capacity between boys and girls.

\subsection{New survey design}

From all this analysis, there appeared some important modifications related to the initial question and a new approach. In particular, it was suggested that the starting hypotheses do not have to be certain and as a consequence, when questions are posed based on these hypothesis student answers might be skewed. In the review to build up the new questionnaire previous comments have been considered.

The questionnaire has been organized into sections that reflect the main areas of interest. The organization of the questions, numbered in sections independently, foresaw that it was possible to use them to be compared with subsequent tests answered by the same population, restricting or enlarging the different sections. These sections are:

a) Relevant data for the study: D1-D2 personal data; D3 filter for 1st year students; D4-D5 actual enrolment at the UPC; D6 anonymous identifier.

b) The referents of the profession related with the degree (R1-R2 for women and R3-R4 for men).

c) Lived experience as UPC student (E1.1-E1.10)

d) Role distribution in mixed work groups (G1 frequency; G2 motivation; G3 roles)

e) Whether or not there are gender biases on the part of students when asked about their perceptions and global opinion (P1 gender-enhanced skills; P2-P5 Assessment on gender equity and comments).

The most significant aspects that have been worked on include:

1 Formal aspects of lexicon and filtering (using Google Forms tools)

2 Adaption to regulations about personal information (including what is mandatory as data, for example, while sex is mandatory gender is a sensitive and personal feeling, which needs to be protected, and, at some point, it could be considered opinion).

3 Less conditioned questions with which students feel more comfortable because they are related to their experiences and less conditioned by social standards and gender stereotypes.

4 Less ambiguous questions that facilitate both students' understanding and the extraction of information in the analysis of the answers. 
5 Non-compulsory opinion questions and, in the appropriate cases, inclusion of options Does not apply, and does not answer, as well as the other options to include answers not previously considered.

As a final step, the opinion of the Feminist Assembly of the ETSEIB was requested again. Also, the questionnaire was tested with a small sample of students. To gather the opinion of the new respondents, an open-response box was included at the end of the questionnaire. In parallel, some personal interviews were held. Two different group of respondents were considered. The first group of respondents had not been exposed to the questionnaire before. This group was selected with the help of Student's Delegation at Escola Politècnica Superior d'Enginyeria de Manresa (EPSEM). These students were enrolled in sixth different engineering degrees in STEM areas. The second group of respondents had already participated in the first analysis of the questionnaire (Section 3.2). These students are enrolled at the Aerospace System Engineering Degree at EETAC.

From the obtained answers, it has been detected that Section $\mathrm{R}$, corresponding to the professional references in society, presented a broad-extension response. Indeed, while some respondents indicated national or international referents, others answered with referents from their immediate environment. According to this, questions R1-R4 would be divided into two: referents in the immediate environment and national or international referents.

In the open-response box, some comments have been provided. Question P1, referring to genderbased skills, keeps on generating some criticism. Students think that they should not evaluate these aspects. Question G3 shows clear differences, which might have statistical significance, in the roles within the work team. This one has not generated criticisms, possibly because it is framed in a specific context and avoids undesired generalizations. In order to avoid hurting student's feelings, P1 could be eliminated or rephrased and G3 could be slightly extended. In G2, about the motivations for the formation of work groups, it appears the option of prioritizing friendships (independently of the gender/sex). However, it is important to note that friendship could be influenced by gender/sex.

We have also checked how the questionnaire appeared on screen in different devices, paying particular attention to how it appeared on mobile phones. For example, although for questions in column/matrix format the mobile screen initially shows only the first two answers, the results show that all answers are replied and there are no significant differences between the frequency of those initially shown and those requiring moving the screen.

\section{CONCLUSIONS}

As a final result, an improved survey to assess student's perceptions of gender mainstreaming in STEM studies has been collaboratively obtained, which may become an essential tool for further studies extended to all the university community. The elaboration process of the questionnaire has had different stages and in general (from the first to the present version) it has been very enriching. We have been able to build a questionnaire by using a cooperative management system, combining discussions between members of the Gender Dimension in Teaching project [4], meetings with student associations and training courses. The final result is substantially better than the first version of the questionnaire and responds to the process of developing a questionnaire from the design of the content, control tests, revisions and further refinements. However, there are still many aspects that could be improved in the questionnaire. Therefore, the questionnaire is seen as something alive, capable of being modified in the future according to the needs and interests of the UPC community.

Currently, the necessary steps to ensure that the questionnaire is officially accepted are being taken, which will allow to collect data at the beginning and at the end of each degree. This way, we will obtain quality indicators for students' perception of gender mainstreaming in UPC teaching. This methodology and objective are applicable to other universities or educational centres, whether they are specialized in STEM or not. However, each area of education will have to adapt the questionnaire according to its own needs and interests.

\section{ACKNOWLEDGEMENTS}

Authors are grateful to (1) Beatriz Galindo and Mireia Ventura for their revisions and suggestions; (2) the Feminist Assembly at ETSEIB, the Students' Delegation at EETAC and the one at EPSEM for their availability and cooperation, and (3) all the members of the Gender Dimension in Teaching project 
carried out at the UPC along 2018-2019 academic year for their cooperation in the first test development.

This work has been carried out within the framework of the Gender Dimension in Teaching project, at UPC-BarcelonaTech, and GEECCO project that has received funding from the European Union's Horizon 2020 research and innovation program under grant agreement No. 741128. The views and opinions expressed herein are those of the authors and do not necessarily reflect the official point of view of the UPC-BarcelonaTech nor the European Commission.

\section{REFERENCES}

[1] J. Lovenduski, "Gendering Research in Political Science," Annu. Rev. Polit. Sci., vol. 1, no. 1, pp. 333-356, 1998.

[2] N. Olmedo-Torre, M. Peña, M. López-Beltrán, M. Sanz, and D. López, "Mentoring female high school students for a STEM career," in IEEE Frontiers in Education Conference, 2018, pp. 1-5.

[3] Universitat Politècnica de Catalunya, "Projectes clau," 2019. [Online]. Available: https://igualtat.upc.edu/ca/projectes-clau

[4] Universitat Politècnica de Catalunya, "Gènere i Docència." [Online]. Available: https://igualtat.upc.edu/ca/projectes-clau/projecte-genere-i-docencia

[5] AQU, "Marc general per a la incorporació de la perspectiva de gènere en la docència universitària." Agència per a la Qualitat del Sistma Universitari de Catalunya, Barcelona, p. 68, 2018.

[6] A. García Holgado, "de Ingeniería de Software I Memoria de resultados," 2017.

[7] M. Delucchi, "Measuring Student Learning in Social Statistics: A Pretest-Posttest Study of Knowledge Gain," Teach. Sociol., vol. 42, no. 3, pp. 231-239, 2014.

[8] M. T. Bartual-Figueras, M. Carbonell-Esteller, A. Carreras-Marín, J. Colomé-Ferrer, and T.-G. Joaquín, "La perspectiva de género en la docencia universitaria de Economía," vol. 10, pp. 92 101, 2018.

[9] T. Christianson, A. and Polfeldt, "Response quality improvement initiatives at Statistics Sweden," in Proceedings of the 2nd International Conference on Methodological Issues in Official Statistics, 1996, pp. 23-24.

[10] H. L and Lindström, Design your questions right. Statistiska centralbyrån, 2004.

[11] U. Engel, B. Jann, P. Lynn, A. Scherpenzeel, and P. Sturgis, Improving Survey Methods. Routledge, Taylor \& Francis Group, 2015. 